\title{
Freely available deforestation alerts can reduce emissions from land-use change
}

\author{
Subscriptions to a free, weekly deforestation alert system available on the simple interface Global Forest Watch \\ reduced deforestation in the protected areas and logging concessions of tropical African forests. This suggests that \\ freely available near-real-time forest monitoring systems can help reduce emissions from deforestation if they are \\ integrated with forest policies.
}

\author{
Fanny Moffette ${ }^{1,2}{ }^{1,}$, Jennifer Alix-Garcia ${ }^{3}$, Katherine Shea ${ }^{4}$ and Amy H. Pickens ${ }^{5}$ \\ BASED ON Moffette, F., Alix-Garcia, J., Shea, K. \& Pickens, A. H. Nat. Clim. Change https://doi.org/10.1038/s41558-020-00956-w (2021).
}

\section{The policy problem}

Deforestation in the tropics has major effects on climate change and biodiversity loss. Furthermore, policies that limit deforestation are more cost effective than interventions to restore landscapes after conversion for agriculture or other uses. Many strategies are available to reduce deforestation creating protected areas, payments for ecosystem services, supply-chain agreements - all of which require that forests be monitored. Until recently, annual deforestation maps released the following year often provided the best monitoring data available. Deforestation rates are generally highest in countries with limited resources to create effective monitoring systems, so making low-cost technologies available may be an important way to support effective policies that aim to prevent deforestation. Using weekly near-real-time deforestation alerts freely available via a platform unaffiliated with any governmental intervention and accessible from anywhere on the globe could have an impact on land-use trends and inform the design of more effective anti-deforestation strategies.

\section{The findings}

Use of the GLAD (global land analysis and discovery) alerts, through subscription to Global Forest Watch, decreased the probability of deforestation in Africa by $18 \%$ within the first two years relative to the average 2011-2016 levels. The simple availability of the alerts did not significantly impact deforestation, and we found no effect on other continents. Effects in Africa were driven by subscriptions within protected areas and logging concessions, which suggests that the alerts were used to fight illegal deforestation. Using the social cost of carbon, we estimate the value of the alert system to be in the range of US\$149-\$696 million. However, the benefits are probably greater since co-benefits such as biodiversity are not included and the effectiveness of using the alerts may be increasing over time. Alert systems are likely to be effective in other regions as long as they provide earlier or more accessible reports of forest loss and policies designed to reduce deforestation are enforced.

\section{Messages for policy}

- Monitoring land-use change is an essential component of any policy that is implemented to reduce deforestation.

- The availability of near-real-time alert systems is not enough to reduce deforestation; they must be used for enforcement and intervention.

- The use of near-real-time satellite-derived measures of deforestation on accessible and easy-to-use geospatial platforms can be an important tool in addressing land-use change.

- The value of satellite-based deforestation monitoring systems in terms of avoided carbon emissions is likely to exceed the costs of design and maintenance.

- Free, high-resolution and high-frequency deforestation alerts can reduce deforestation in settings where they provide new information and policymakers are able to integrate them into enforcement policy.

\section{The study}

We estimated the impact of GLAD alerts on deforestation across 22 tropical countries using data from 2011 to 2018. Figure 1 shows the African study region, its subscriptions and examples of GLAD alerts. We used a random sample of $1 \times 1 \mathrm{~km}$ grid cells from all countries that began receiving alerts prior to 2018 . We first examined whether having access to GLAD alerts decreased deforestation using the gradual rollout of the alert system. Second, we studied whether using GLAD alerts via subscription changed deforestation rates. In the first case, we used the country as the unit of analysis, and in the second, the grid-cell. In both analyses, we estimated the impact by comparing trends in areas covered earlier with those covered later, controlling for time-invariant 


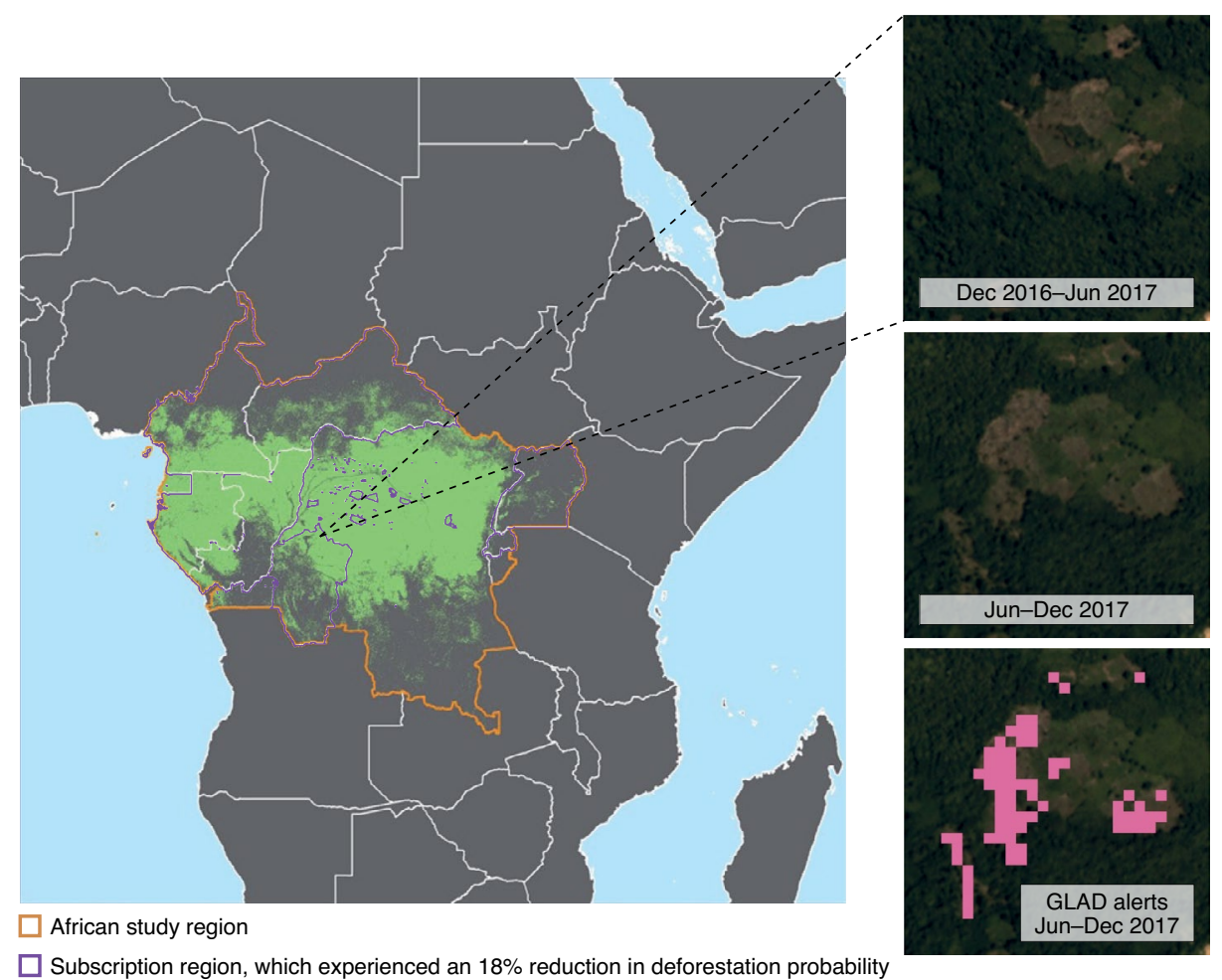

$\square$ Subscription region, which experienced an $18 \%$ reduction in deforestation probability

Tree cover

Fig. 1 | African study region, its subscriptions and examples of GLAD alerts. Left, African study region and the region with subscriptions overlaid on a map of the forest evaluated in this study. Right, example of forest loss detected by GLAD alerts centred at $1.35^{\circ} \mathrm{S}, 19.33^{\circ} \mathrm{E}$. Images obtained with permission from www.globalforestwatch.org.

characteristics that influence deforestation, general macroeconomic events and weather, as well as for confounding variation from changes in transport or production technologies over time.

Published online: 28 October 2021

https://doi.org/10.1038/s41558-021-01195-3

\section{Further reading}

Assunção, J., Gandour, C. \& Rocha, R. DETERring Deforestation in the Amazon: Environmental Monitoring and Law Enforcement (Climate Policy Initiative, 2017); https:/climatepolicyinitiative.org/wp-content/uploads/2013/05/DETERringDeforestation-in-the-Brazilian-Amazon-Environmental-Monitoring-and-LawEnforcement-Technical-Paper_Feb2017.pdf

Evidence of the impact of the near-real-time deforestation alert system DETER, which was created by and provided to the Brazilian government to monitor the Brazilian Amazon.

Hansen, M. C. et al. High-resolution global maps of 21st-century forest cover change. Science 342, 850-853 (2013).

Global annual data on tree-cover loss.
Hansen, M. C. et al. Humid tropical forest disturbance alerts using Landsat data. Environ. Res. Lett. 11, 34008 (2016).

This study describes the methodology used to create the GLAD alerts; our research examines the impact of these alerts.

Slough, T., Kopas, J. \& Urpelainen, J. Satellite-based deforestation alerts with training and incentives for patrolling facilitate community monitoring in the Peruvian Amazon. Proc. Natl Acad. Sci. USA https://doi.org/10.1073/ PNAS.2015171118 (2021).

A randomized control trial that analysed the effect of training and incentivising indigenous communities in Peru to use the deforestation alerts from Global Forest Watch.

\section{Acknowledgements}

The authors acknowledge funding from the World Resources Institute. The organisation reviewed the paper but had no input in the study design nor influence on the presentation of results.

\section{Competing interests}

The authors declare no competing interests. 